\title{
THE INFLUENCE OF CAFFEINE INGESTION ON INCREMENTAL TREADMILL RUNNING
}

\author{
L. R. McNAUGHTON, PhD
}

Tasmanian State Institute of Technology

\begin{abstract}
The aim of this study was to determine the effects of caffeine ingestion on estimated substrate utilisation during treadmill running at an initial level of $70 \%-75 \%$ of maximal oxygen consumption after which subjects ran to exhaustion. Twelve subjects undertook either a control, placebo, a small $\left(10 \mathrm{mg} \cdot \mathrm{kg}^{-1}\right)$ or a large $\left(15 \mathrm{mg} \cdot \mathrm{kg}^{-1}\right)$ dose of caffeine in a double-blind design to determine whether caffeine affected the substrate usage during running. Venous blood was collected prior to and during the experimental runs and was later analysed for free fatty acids (FFA), glycerol, triglycerides, lactate and glucose concentrations. The results of this experiment suggest that maximal running performance can be increased by large doses of caffeine. Furthermore, the subjects' respiratory exchange ratios were lower and FFA concentrations were higher following the ingestion of large amounts of caffeine than during other trials, suggesting that a larger proportion of energy was derived from fat being used preferentially during the trial following ingestion of this large dose of caffeine. The subjects rating of perceived exertion (RPE) were lower following the ingestion of a large dose of caffeine than it was in any of the other trials. This study differs from others in this area in so much that caffeine has been found to have positive effects during maximal running when used in large doses.
\end{abstract}

Key words: Running, Caffeine, Fat metabolism, Perceived exertion.

\section{INTRODUCTION}

The effects of caffeine on endurance during muscular exercise has been reported as being both beneficial (Costill et al, 1978; Ivy et al, 1979a; Essig et al, 1980), and of no benefit (Perkins and Williams, 1975; Powers et al, 1983; Casal and Leon, 1985). Ingestion of caffeine prior to exercise has been shown to elevate significantly plasma levels of free fatty acids (FFA) and glycerol (Costill et al, 1978; Ivy et al, 1979b). An increase in circulating FFA is believed to have a sparing effect on muscle glycogen and hence delay exhaustion during prolonged exercise (Issekutz et al, 1966; Rennie et al, 1976). This glycogen-sparing effect probably occurs because it is known that an accumulation of FFA reduces the rate of glycolysis via inhibition of phosphofructokinase (PFK; Ramadoss et al, 1976). This study was conducted to determine the affects of caffeine ingestion on estimated substrate utilisation during treadmill running at an initial level of $70 \%-75 \%$ of maximal oxygen consumption $\left(\mathrm{VO}_{2}\right.$ max) for $\mathbf{4 5}$ minutes after which subjects ran to exhaustion.

\section{METHODS}

Prior to participation in the study twelve male athletes signed informed consent forms which outlined the procedures to be taken and the possible risks involved. All subjects were trained and were participating in various recreational team sports. Following a routine physical examination at baseline levels each subject underwent a maximal treadmill test. The test was preceded by a ten min warm up period during which treadmill speed was maintained at a constant speed of $3.33 \mathrm{~m} . \mathrm{sec}^{-1}$ (12 km.hr-1) and at zero per cent grade. Treadmill speed was then increased to $3.67 \mathrm{~m} . \mathrm{sec}^{-1}\left(13.2 \mathrm{~km} . \mathrm{hr}^{-1}\right)$ for six mins at zero per cent grade, after which the grade was increased by two per cent at two min intervals. When the grade reached six

Address for correspondence:

Dr. Lars McNaughton

Tasmanian State Institute of Technology

PO Box 1214

Launceston

Tasmania 7250

AUSTRALIA per cent it was held constant and the speed was increased by $0.14 \mathrm{~m} . \mathrm{sec}^{-1}\left(0.5 \mathrm{~km} \cdot \mathrm{hr}^{-1}\right)$ at the end of each subsequent two minute period. The test was terminated when the subjects informed the investigator that they could no longer proceed.

Respiratory data was collected during exercise tests by open circuit spirometry using an Applied Electrochemistry Oxygen analyser (Model S3A) and a Binos 1 carbon dioxide analyser. Prior to the testing sessions each of the analysers was calibrated using $100 \%$ nitrogen, two known mixtures of carbon dioxide, oxygen and nitrogen and room air. Subjects breathed through a mouthpiece connected to a 3-way Koegel valve supported by a lightweight plastic helmet which was attached directly to the mixing chamber by $3 \mathrm{~cm}$ diameter low resistance corrugated tubing. Heart rates were monitored continuously by electrocardiogram (Med Apps Mk 24) throughout the tests with a hard copy being obtained during the last ten seconds of each stage.

Following the maximal oxygen consumption $\left(\mathrm{VO}_{2} \max \right)$ test the subjects made four additional visits for experimental treadmill trials to test the effect of caffeine on substrate utilisation. Subjects reported to each run after at least a six hour fast and completed all runs within a two week period with at least two days between each run. Each of the test runs was completed at a speed which, from the previous maximal exercise test, it was calculated would elicit an intensity of approximately $70 \%-75 \%(X=72 \% \pm$ $1.2 \%$ ) of $\mathrm{VO}_{2}$ max, for a period of 45 mins. After this, treadmill speed was increased every two mins by $0.14 \mathrm{~m} . \mathrm{s}^{-1}$ $\left(0.5 \mathrm{~km} . \mathrm{hr}^{-1}\right)$ until the subjects informed the investigator that they could no longer continue.

Sixty mins prior to each of the experimental treadmill runs the subjects consumed one of four test beverages: (a) $350 \mathrm{ml}$ of warm water, (b) $5 \mathrm{~g}$ of decaffeinated coffee in $350 \mathrm{ml}$ of warm water; (c) $10 \mathrm{mg} \cdot \mathrm{kg}^{-1}$ caffeine with $5 \mathrm{~g}$ of decaffeinated coffee in $350 \mathrm{ml}$ of warm water and (d) $15 \mathrm{mg} \cdot \mathrm{kg}^{-1}$ caffeine with $5 \mathrm{~g}$ decaffeinated coffee in $350 \mathrm{ml}$ of warm water. These represent the Control (C), Decaffeinated (D), Caffeine 1 (CA1) and Caffeine 2 (CA2) trials respectively. The control run was always the first of the runs and the others were made in a random doubleblind fashion. Subjects were allowed ten mins to consume 
the test beverage and were then given fifty mins to rest before the test.

During each experimental treadmill run a rating of perceived exertion (RPE) was recorded just prior to the collection of blood samples (Borg, 1973). This measure was also carried out at the end of each experimental run.

Venous blood was collected from each of the subjects in the sitting position when they first entered the laboratory (-60 mins), prior to the exercise test $(0 \mathrm{mins})$ and at 15,30 and $\mathbf{4 5}$ mins. Blood collection was not carried out at the end of the running test since the subjects performed for different amounts of time. All samples were analysed for serum FFA, serum glycerol, serum lactate, plasma glucose and plasma triglycerides. These were analysed by methods described by Dalton and Kowalski, 1967; Bergmeyer, 1974; Guttman, 1974; Clark, 1973 and Wahlefeld, 1974 respectively. In order to determine statistical significance between the trials at the various time intervals a repeated measures analysis of variance was conducted and the 0.05 level of significance was chosen (Keppel, 1982). Data on the RPE was analysed in the same manner.

\section{RESULTS}

The baseline data on the subjects are shown in Table I. The average $\mathrm{VO}_{2}$ max for the subjects was $56.6 \pm$ $1.3 \mathrm{ml}^{.} \mathrm{kg}^{-1} \mathrm{~min}^{-1}$ with a range of 53.9 to $60.2 \mathrm{ml} \mathrm{kg}^{-1} \mathrm{~min}^{-1}$. Table II shows the differences in time to exhaustion for the subjects in the four conditions. There was a statistically significant difference between the CA2 and the C, D and CA1 ( $p<0.05$ ). That is the subjects who were given the large doses of caffeine performed for a longer time period (to exhaustion) than they did when given the smaller dose of caffeine, the placebo or during the control run.

\section{TABLE}

Characteristics of the subjects (N = 12) and average running speed for $75 \%$ of maximum oxygen uptake $\left(\mathrm{VO}_{2} \mathrm{max}\right)$.

(Values are means \pm SE)

\begin{tabular}{ccccc}
\hline $\begin{array}{c}\text { Age } \\
(\mathrm{yr})\end{array}$ & $\begin{array}{c}\text { Height } \\
(\mathrm{m})\end{array}$ & $\begin{array}{c}\text { Weight } \\
(\mathrm{kg})\end{array}$ & $\begin{array}{c}\mathrm{VO}_{2} \max \\
\left(\mathrm{ml}^{\mathrm{k}} \mathrm{kg}^{-1} \mathrm{~min}^{-1}\right)\end{array}$ & $\begin{array}{c}75 \% \text { max speed } \\
\left({\left.\mathrm{m} . \mathrm{s}^{-1}\right)}^{-}\right.\end{array}$ \\
\hline $22 \pm 1.2$ & $1.79 \pm 0.05$ & $65.8 \pm 2.7$ & $56.6 \pm 1.7$ & $226 \pm 7.8$ \\
\hline
\end{tabular}

TABLE II

Time to exhaustion of the subjects in the four conditions (" $p=0.05$ from all other tests)

\begin{tabular}{lc}
\hline $\begin{array}{l}\text { Condition } \\
(\mathrm{N}=12)\end{array}$ & $\begin{array}{c}\text { Time to Exhaustion } \\
\text { (min:secs) }\end{array}$ \\
\hline Control (C) & $48: 21$ \\
Decaffeinated (D) & $48: 03$ \\
Caffeine (CA1) & $48: 49$ \\
Caffeine (CA2) & $50: 52^{*}$
\end{tabular}

Fig. 1 shows the heart rate values for the four conditions. There was a significant difference $(p<0.05)$ between the CA2 and the C, D, and CA1 trials at the 0 time level. This difference disappeared during exercise. Respiratory exchange ratio (R) values, which can be seen in Table III suggests that there was a sparing of carbohydrate following
CA2 ingestion. There was also a significant difference in $\mathrm{VO}_{2}$ between both $\mathrm{C}$ and $\mathrm{D}$ and CA2 trials at the $30 \mathrm{~min}$ and 45 min marks (see Table III). This difference was also found at the end of each run.

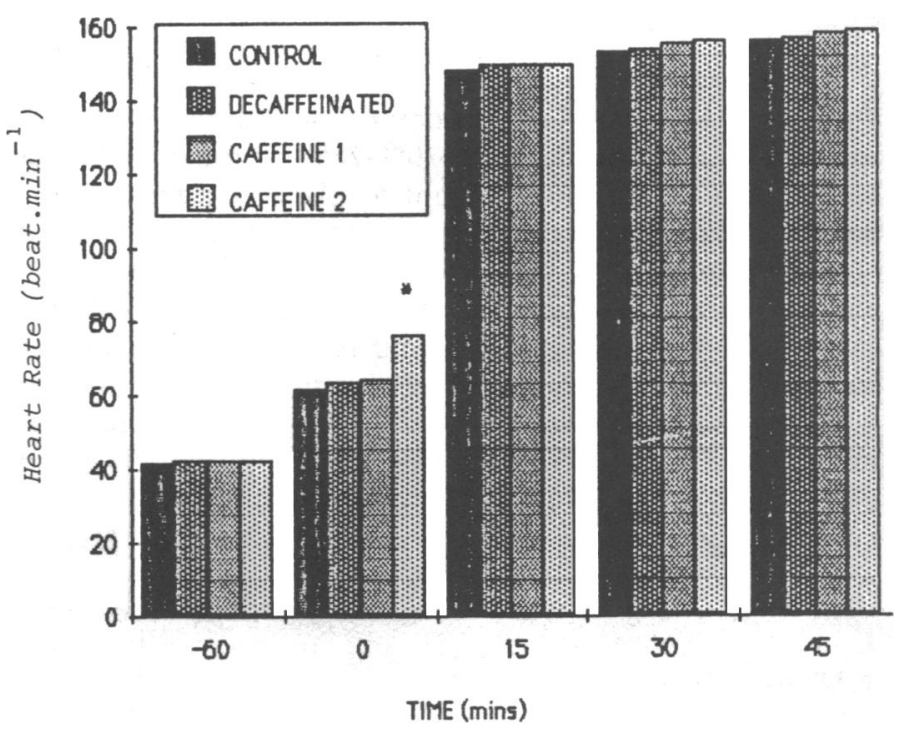

Fig. 1: Heart rate values prior to and during each trial.

*Significantly different from the Control, Decaffeinated and Caffeine 1 values, $p<0.05$.

TABLE III

Oxygen uptake $\left(\mathrm{VO}_{2}\right)$ and respiratory exchange ratio values at 15,30 and 45 minutes of each trial. (Values are mean $\pm S E M, n=12$ )

\begin{tabular}{lcccccc}
\hline & \multicolumn{3}{c}{} & \multicolumn{3}{c}{ Respiratory Exchange } \\
Trial & \multicolumn{2}{c}{$\mathrm{VO}_{2}\left(\mathrm{ml}^{\prime} \mathrm{kg}^{-1} \mathrm{~min}^{-1}\right)$} & \multicolumn{3}{c}{ Ratio } \\
& $15 \mathrm{~min}$ & $30 \mathrm{~min}$ & $45 \mathrm{~min}$ & $15 \mathrm{~min}$ & $30 \mathrm{~min}$ & $45 \mathrm{~min}$ \\
\hline Control & 38.3 & 40.0 & 41.4 & 0.93 & 0.93 & 0.93 \\
& $(3.8)$ & $(3.7)$ & $(3.7)$ & $(0.03)$ & $(0.03)$ & $(0.03)$ \\
Decaffeinated & 38.5 & 40.0 & 41.3 & 0.93 & 0.93 & 0.93 \\
& $(3.3)$ & $(3.3)$ & $(3.4)$ & $(0.02)$ & $(0.02)$ & $(0.02)$ \\
Caffeine 1 & 38.5 & 39.8 & 41.5 & 0.93 & $0.93^{* *}$ & 0.93 \\
& $(3.4)$ & $(3.3)$ & $(3.4)$ & $(0.02)$ & $(0.02)$ & $(0.02)$ \\
Caffeine 2 & 38.5 & 40.3 & 42.5 & 0.92 & $0.90 * *$ & $0.89 * * t$ \\
& $(2.8)$ & $(2.8)$ & $(2.7)$ & $(0.02)$ & $(0.02)$ & $(0.01)$ \\
\hline
\end{tabular}

†Time effect $(p<0.05)$

* * Significantly different from the Control/Decaffeinated and Caffeine 1 trials $(p<0.05)$

Changes in blood and serum parameters from the beginning ( -60 mins) of the test period to the end of the exercise collection test period (45 mins) are shown in Figs. 2 to 5. FFA (Fig. 2) increased in the $60 \mathrm{~min}$ period following caffeine ingestion in both the CA1 and CA2 trials $(-60$ mins to 0 mins). At the start of exercise the control values averaged $0.36 \mathrm{mmol}^{-1}-1$ while at time 0 the CA2 trial averaged $0.81 \mathrm{mmol}^{-1} \mathrm{I}^{-1}$. The CA1 and CA2 trials were both significantly different from both the control and $D$ trials at the start of exercise $(p<0.05)$.

In the first 15 mins of work serum FFA concentrations decreased in all of the experimental trials. The decrease in these values for the two caffeine trials was $24 \%$ and $32 \%$ for CA1 and CA2 respectively while in the $C$ trial it was $8 \%$ and in the $D$ trial it was $14 \%$. The drop in FFA concentrations in the two caffeine trials was once again significantly different 
from both the $C$ and $D$ trials $(p<0.05)$. After this initial drop in FFA concentrations, values again increased. FFA levels in the $\mathrm{CA} 1$ and $\mathrm{CA} 2$ trials remained significantly higher than in the $C$ or $D$ trials for the total period of the exercise $(p<0.05)$.

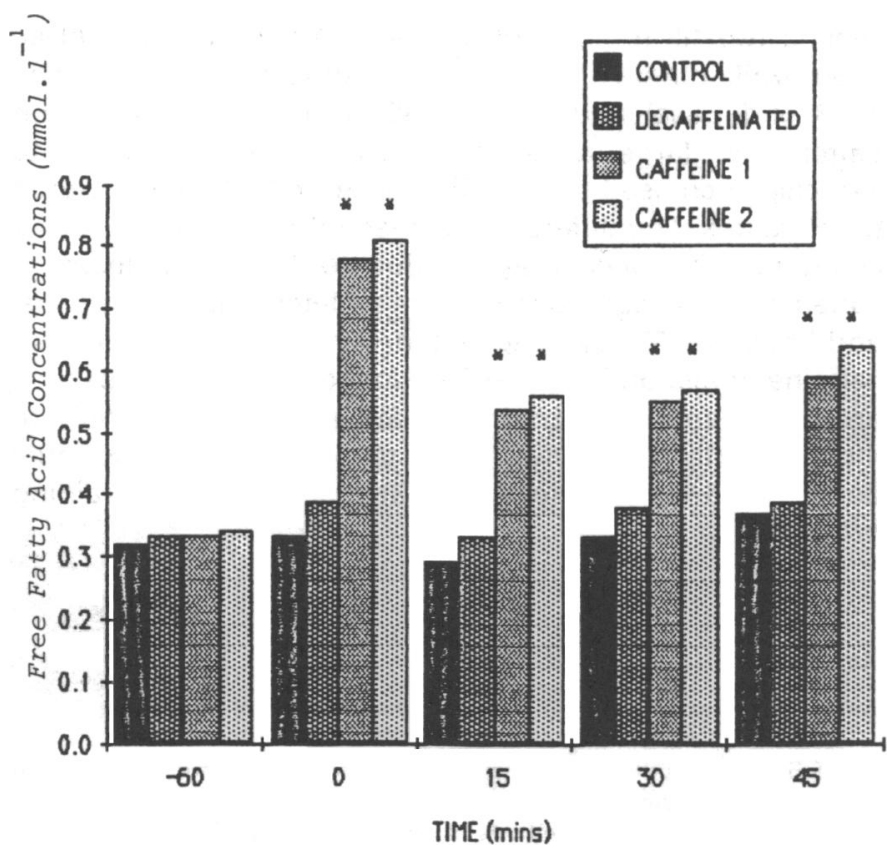

Fig. 2: Serum free fatty acid concentrations prior to and during each trial. *Significantly different from both the control and decaffeinated trials, $p<0.05$.

Glycerol values in all trials increased with exercise (see Fig. 3). The only significant differences were between the CA2 trial and the C, D and CA1 trials at the $\mathbf{4 5}$ min test mark $(p<0.05)$. Fig. 4 shows that there were no significant changes in blood lactate concentration between trials although in both the CA1 and CA2 trials there was a small but not significant decrease in the lactate levels when compared to both the $C$ and $D$ trials. Due to the upward rise in all trials of lactate during the exercise collection period ( 0 mins to 45 mins) there was a significant $(p<0.05)$ time effect.

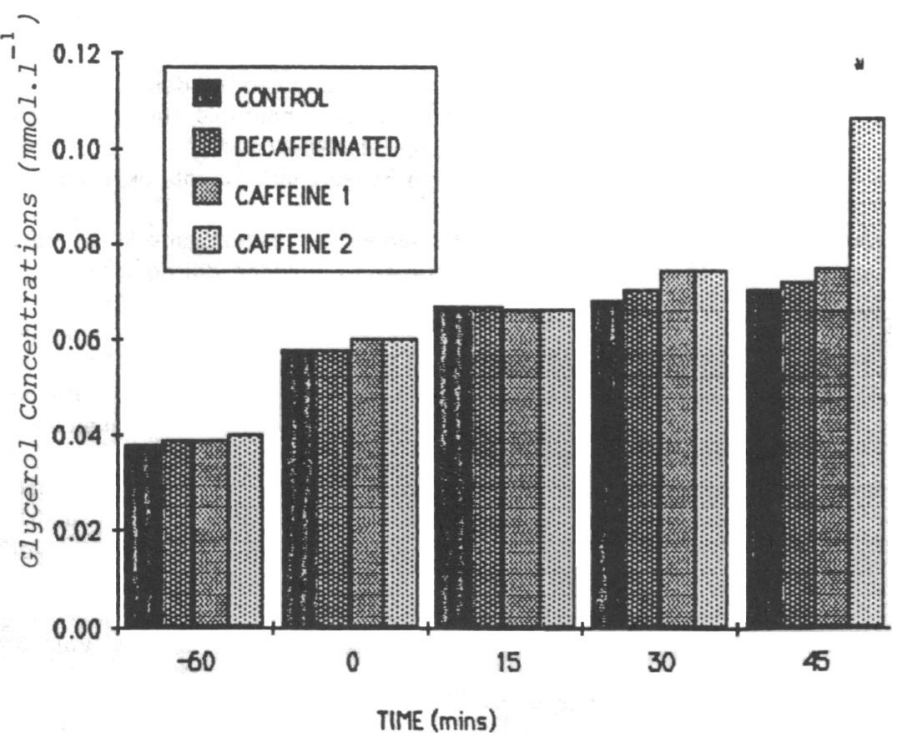

Fig. 3: Serum glycol concentrations prior to and during each trial. *Significantly different from all other trial values at this time level, $p<0.05$.

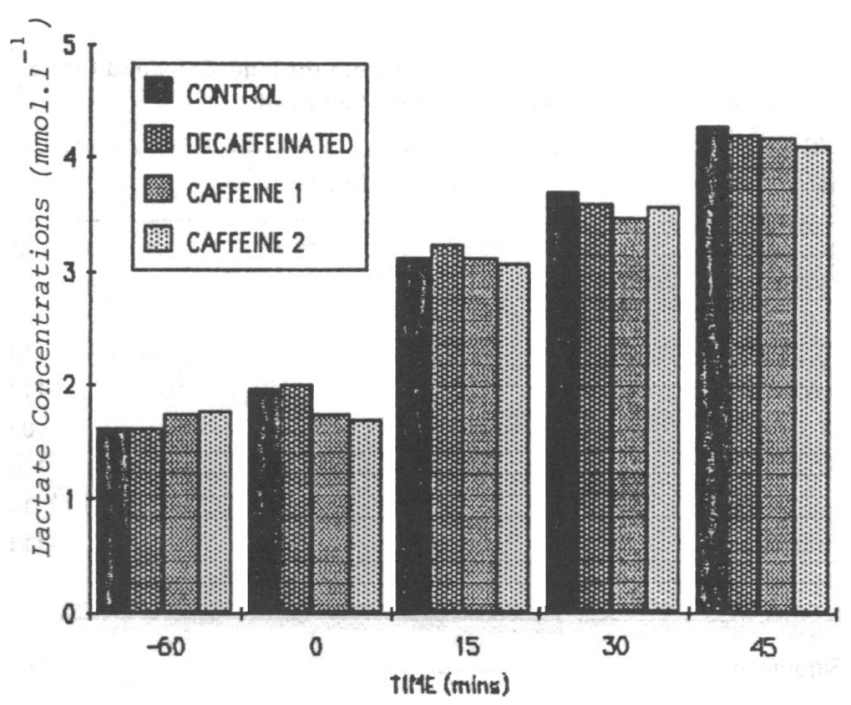

Fig. 4: Serum lactic acid concentrations prior to and during each trial. Significant time effect, $p<0.05$.

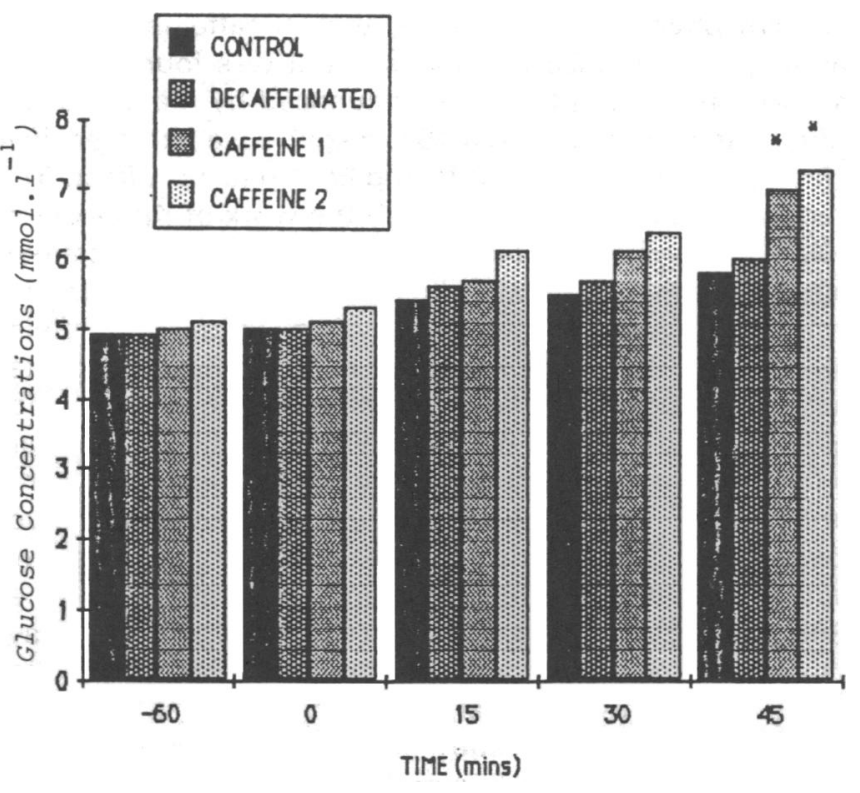

Fig. 5: Serum glucose concentrations prior to and during the running test. * Significantly different from values during $C$ and $D$ trials, $p<0.05$.

Both the glucose and triglyceride concentrations increased significantly from 0 to $\mathbf{4 5}$ mins, that is there was a statistically significant time effect $(p<0.05)$. A comparison between trials at the differing time levels for glycose only, shows that the $45 \mathrm{~min}$ values for CA1 and CA2 were both significantly different from the comparable value during the $C$ trial ( $p<0.05$ ). Triglyceride concentrations, which are shown in Table IV, increased during the CA2 trials following ingestion, by approximately ten per cent but this was not statistically significant.

During the CA2 trial the athlete's RPE was lower at all times than during the $C, D$ and $C A 1$ trials. A significant difference was seen $(p<0.05)$. There was a significant time effect $(p<0.05)$ for RPE.

\section{DISCUSSION}

Coffee has become popular in recent years as an ergogenic aid in long distance running and cycling events, based upon 
TABLE IV

Serum triglyceride concentrations from the ingestion point to the 45 minute collection point

\begin{tabular}{lrrrrc}
\hline Trial & \multicolumn{5}{c}{ Time (min) } \\
\hline & -60 & 0 & 15 & 30 & 45 \\
\hline Control & 9.0 & 9.0 & 10.2 & 11.7 & $12.1^{*}$ \\
& 1.0 & 1.1 & 1.1 & 1.0 & 1.0 \\
Decaffeinated & 9.1 & 9.0 & 10.4 & 10.8 & $11.6^{*}$ \\
& 0.8 & 0.8 & 0.6 & 0.6 & 0.8 \\
Caffeine 1 & 8.9 & 9.0 & 9.9 & 10.7 & $11.6^{*}$ \\
& 0.6 & 0.7 & 0.7 & 1.1 & 1.2 \\
Caffeine 2 & 9.1 & 10.2 & 10.6 & 11.1 & $11.9^{*}$ \\
& 1.0 & 1.1 & 1.1 & 1.2 & 1.0 \\
\hline
\end{tabular}

*Significantly different from 0 min sample, $p<0.05$

evidence that caffeine increases lipid utilisation in trained cyclists (Costill et al, 1978 and Essig et al, 1980). The data of this experiment supports the hypothesis that caffeine will improve physical performance, that is caffeine improved running performance to exhaustion. It was found that the increase in running time was influenced by the amount of caffeine ingested, that is, a $15 \mathrm{mg} \cdot \mathrm{kg}^{-1}$ dose had a positive effect whereas a dose of $10 \mathrm{mg} \cdot \mathrm{kg}^{-1}$ had no effect. This study was not in agreement with the work of Knapik et al, (1983) who found that in trained male runners, caffeine failed to change estimated lipid oxidation during running, although FFA levels were elevated following caffeine ingestion. Furthermore Knapik et al (1983) have suggested that the failure of caffeine to affect substrate utilisation might be linked to exercise modality, specifically in regard to the amount of muscle mass involved which is greater in running than in cycling. The results of the present study however conflict with this statement. Several studies have found that caffeine effects FFA mobilisation (Bellet et al, 1965; Bellet et al, 1968 and Essig et al, 1980) and there have also been studies supporting increased FFA mobilisation during exercise (Costill et al, 1978 and Essig et al, 1980). The results of this present study are in agreement with these latter studies. Increased FFA mobilisation may be due to the inhibition of carbohydrate use by modification of the PFK and pyruvate dehydrogenase reactions during high rates of fat oxidation (Issekutz et al, 1966; Rennie et al, 1976). During exercise it was found that there was an initial drop in FFA concentrations followed by an increase. This response is somewhat typical and is probably due to the initial disproportionate removal of FFA from the blood relative to that mobilised and entering the circulation (Essig et al, 1980).

Although no measurements of muscle glycogen were made in this study it was hypothesised that the use of muscle glycogen was spared following ingestion of a large amount of caffeine and physical working capacity was enhanced due probably to the preferential use of fat by the tissues. It is also possible that there was increased esterification of FFA since pre-exercise triglyceride concentrations were increased by ten per cent. The finding that $R$ values were lower during the CA2 trial supports the hypothesis that fat was being preferentially used by the tissues.

In conclusion, several studies have shown a beneficial effect of caffeine for increased maximal performance during cycling (Costill et al, 1978; Ivy et al, 1979 and Essig et al, 1980) while others have reported no difference (Knapik et al, 1983 and Casal and Leon, 1985). This study found that caffeine in large doses $\left(15 \mathrm{mg} \cdot \mathrm{kg}^{-1}\right)$ an hour prior to exercise, increased serum FFA concentrations and lowered the $R$ values. The difference between this and other studies citing no difference may be due to the large doses of caffeine (15 mg. $\mathrm{kg}^{-1}$ ) given to the athletes. Further, as Casal and Leon (1985) have suggested, it might be possible that caffeine ingestion has an effect only on those athletes who are not of an elite nature and have not had the benefit of increased lipolytic enzyme activity and mitochondrial density and size (Holloszy, 1973) that endurance training brings about.

\section{References}

Bellet, S., Kershbaum, A. and Aspe, J., 1965 "The effect of caffeine on free fatty acids". Arch.Intern.Med. 116: 750-752.

Bellet, S., Kershbaum, A. and Finck, E., 1968 "Response of free fatty acids to coffee and caffeine". Metabolism 17: 702-707.

Berghmeyer, H. V., 1974. Methods of enzymatic analysis, Academic Press, New York, 1404-1408.

Borg, G. A., 1973 "Perceived Exertion: a note on history and methods" Med.Sci.Sports Exerc. 5: 90-93.

Casal, D. C. and Leon, A. S., 1985 "Failure of caffeine to affect substrate utilisation during prolonged running". Med.Sci.Sports Exerc. 174-179.

Clark, L. C., 1973 "A polargraphic enzyme electrode for measurement of oxidase substrate" In: Oxygen Supply, Kessler, M. (Ed.), Urban and Schwarzenbergs, Munich.

Costill, D. L., Dalsky, G.I P. and Fink, W. J., 1978 "Effect of caffeine ingestion on metabolism and exercise performance". Med.Sci.Sports Exerc. 10: 155-158.

Dalton, C. and Kowalski, C., 1967 "Automated calorimetric determination of free fatty acids in biologic fluids". Clinical Chemistry 13: 744-751.

Essig, D., Costill, D. L. and van Handel, P. J., 1980 "Effects of caffeine ingestion on utilization of muscle glycogen and lipid during leg ergometer cycling". Int.J.Sports Med. 1: 86-90.

Guttman, H., 1974 In: Methods of Enzymatic Analysis, Vol. 3. H. Bergomeyer (Ed.), Academic Pres, New York, 1464-1467.

Issekutz, B., Miller, H. I. and Rodahl, K. (1966), Lipid and carbohydrate metabolism during exercise". Fed.Proc. 25: 1415-1420.

Ivy, J. L., Costill, D. L., Fink, W. J. and Lower, R. W., 1979a "Influence of caffeine and carbohydrate feedings on endurance performance". Med.Sci.Sports Exerc. 11: 6-11.

IVy, J. L., Costill,D. L., Essig, D. A., Lower, R. W. and van Handel, P. J., 1979b "The relationship of blood lactate to the anaerobic threshold and hyperventilation". Med.Sci.Sports Exerc. 11: 96-97.

Keppel, G., 1982. Design and Analysis: A Researcher's Handbook, PrenticeHall Inc., New Jersey, 381-479.

Knapik, J. J., Jones, B.H., Toner, M. M., Daniels, W. L. and Evans, W. J., 1983 "Influence of caffeine on serum substrate changes during running in trained and untrained individuals". Biochem. Exercise 13: 514-519.

Perkins, R. and Williams, M. H., 1975 "Effect of caffeine upon maximal muscular endurance of females". Med.Sci.Sports 7: 221-224.

Powers, S. K., Byrd, R.J., Tulley, R. and Callender, T., 1983 “Effects of caffeine ingestion on metabolism and performance during graded exercise". Eur.J.App.Physiol. 50: 301-307.

Ramadoss, C. S., Uyeda, K. and Johnson, J. M., 1976 "Studies on the free fatty acid inactivation of phosphofructokinase" J.Biol.Chem. 251: 98-107

Rennie, M. J., Winder, W. W. and Holloszy, J. O., 1976 "A sparing effect of plasma free fatty acids on muscle and liver glycogen content in exercising rats". Biochem.J. 156: 647-655.

Wahlefeld, A. W. 1974 In: Methods of Enzymatic Analysis Vol. 3, H. Bergomeyer (Ed.), Academic Press, New York, 1831-1835. 